\title{
ANALYTICS IN BEHAVIORAL INTERVENTION EDUCATION
}

\author{
Thilini Ariyachandra, Xavier University, ariyachandrat@xavier.edu \\ Joseph Landers, Xavier University, landersjc@gmail.com \\ Mark Frolick, Xavier University, frolick@xavier.edu
}

\begin{abstract}
Students with emotional, behavioral or developmental problems are on the rise, and public schools are increasingly turning to special education charter schools and independent behavioral intervention focused private schools. Instructors working in the front lines of these issues provide the best possible solution to behavioral interventions. Collecting data surrounding the intervention situation can be most helpful to enhance intervention based education. BI infrastructure offers a great solution to enhance the special education process. The expanded data availability and ability to see trends and underlying data as never before offers a better understanding of how instruction affects learning and behavior treatment. Through the embracing of the collection and reporting of all the students data, all stakeholders will be better informed to make the right decisions, at the right time and ensure the student is in the proper placement for his/her current state.
\end{abstract}

Keywords: Analytics, Business Intelligence, Special Education, Behavioral Intervention

\section{THE EMOTIONAL, BEHAVIORAL \& DEVELOPMENTAL PROBLEMS EDUCATION LANDSCAPE}

Students with emotional, behavioral or developmental problems is on the rise (National Survey of Childhood Health Data, 2009/10), and public schools are increasingly turning to special education charter schools and independent behavioral intervention focused private schools (Scientific Learning, 2015). These independent schools are often non-profit and work from a behavior intervention theory to address the student's behaviors, and provide them with the necessary skills to reduce their overall problem severity and increase their ability to function in a normal setting. School districts demand proof of a student's improved behaviors prior to accepting them back, and the use of data to influence treatment as well as show improvement has room to grow. This evidence is based on applying and recording positive behavior support and functional behavior assessments in schools.

This data has experienced increase in capture since the federal mandate for use of evidence-based practice in the No Child Left Behind Act of 2001. "An evidence-based practice was defined as one supported by empirical research and professional wisdom so that research-based instructional methodologies could be implemented in the unique systems represented by each preK-12 public school" (Whitehurst, 2002). Data collection in schools has been defined as "the systematic gathering of information designed to verify that student learning occurs" (Gunter, 2001). The data is being collected and to some degree used for instructional planning, and trend analysis. However, "selection of instructional methodologies remains more dependent on the professional wisdom aspect of evidence-based than on the empirically supported component" (Whitehurst, 2002). The gains that could be realized through proper data based decision making based on business intelligence remain unfulfilled.

There exists a gap in application of evidence-based researched best practices and implementation at the education level. "At least some of the challenges faced in special education, such as the disproportionate representation of culturally and linguistically diverse students, the gap between research and practice, and inequitable educational opportunities, can be explained in part by a research gap, or, in other words, a failure to conduct the different types of research best suited for addressing the complicated issues faced in schools" (Boardman, 2011). This gap between research and practice leads to overreliance on teachers' intuition and not on evidence based results. This gap is evident in a survey of teachers, school psychologists, and Kavale and Forness to rank order the effectiveness (table 1) (Kavale and Forness, 2000). Here we see that special education teachers' rankings of instructional strategies are 
not in agreement with research based effective strategies. The strategies found to have large effect sizes, are not consistently ranked in the top of the list for teachers except Direct Instruction. Two strategies with the largest effect sizes, Mnemonic strategies (1.62) and Applied Behavioral Analysis (.93) are ranked in the bottom half of teachers effectiveness lists. Teachers make a big impact on where education dollars are spent in special education schools. The use of data would drive them to make better investments in educational practices that are proven effective.

Table 1. Rank Order of Frequecy for the Survey Respondents and Effectiveness

\begin{tabular}{llll}
\hline Rank & Special Education Teachers & School Psychologists & Kavale and Forness \\
\hline 1 & Direct Instruction & Direct Instruction & Mnemonic strategies $^{\mathrm{a}}$ \\
2 & Modality Instruction & Formative assessment & Applied behavior analysis $^{\mathrm{a}}$ \\
3 & Social skills training & Mnemonic strategies & Direct instruction $^{\mathrm{a}}$ \\
4 & Formative assessment & Social skills training & Formative assessment $^{\mathrm{b}}$ \\
5 & Applied behavior analysis & Applied behavior analysis & Psycholinguistic training $^{\mathrm{c}}$ \\
6 & Mnemonic strategies & Modality Instruction & Social skills training \\
7 & Psycholinguistic training & Psycholinguistic training & Modality Instruction $^{\mathrm{c}}$ \\
8 & Perceptual-motor training & Perceptual-motor training & Perceptual-motor training $^{\mathrm{c}}$ \\
\hline Adopted from Kavale and Forness (2000) & & \\
\hline
\end{tabular}

Recently there have been some attempts to incorporate a more analytical approach in special education. Chen (2015) describes the use of video based story telling tool that captures data used to assess the performance of autism spectrum disorder (ASD) students. Another study describes the use of smart devices in the data collection and assessment of literary skills of ASD children (Kim et al 2015). Snappet, an adaptive educational technology, displays real time data of students engaged in solving mathematical problems that is easily transferred to an instructor's dashboard. It helps students with a wide range of math skills to engage in mathematics (Molenar and van Campen 2016). However, examples of the use of information systems in general and data analytics specifically are very sparse (Burns 2015). Efforts have been made to integrate data on care, instructors, therapists, appointments, as it relates to a student requiring behavioral intervention. Autism management systems can now capture data that can be used for advanced analytics; however, such advances are still in its infancy (Burns 2015). Education in general has begun to explore the power of analytics and business intelligence. Learning analytics, which first saw light in higher education, now is going through rapid adoption in K-12 education as well (Ebner and Schon 2013). A wide variety of applications have become currently available to train and test competence of students.

\section{BI IN EDUCATION}

Primary and secondary education institutions are utilizing business intelligence or at least a watered down version of it. Information technology and learning analytics can give instructors the ability to examine "a wider radius of perceive specific behavior" and enables them to storing and processing all the relevant data (Ebner and Schon 2013). According to Phil Long and George Siemens (2011) the most dramatic factor shaping the future of higher education is "something that we can't actually touch or see: big data and analytics." In the education industry, it is referred to as data-driven decision making, or evidence-based instruction. However the effectiveness and uses of the data leave much to be desired. Data collection and its use are the biggest barriers to true evidence-based instruction. While data collection is the foundation of informed teacher decision making according to Gunter (2003), without proper collection, further analysis is impossible.

Student Information Systems (SIS) and Learning Management Systems (LMS), however these are tailored to traditional schools and do not meet all the needs for data capture in the special education setting. These systems focus on descriptive student data such as attendance, demographics, state reporting needs, as well as classroom data such as assignments, lesson planning and tests. This data is usually housed in two separate applications with limited ability to access the data in raw form. These data collection opportunities do not provide the more robust needs of the special education student. Often data is collected on these students hourly and in some cases by the minute. This data usually ends up in a spreadsheet. 
Data analysis varies by collection form. The IEP has been required since 1975 requiring two things for IEP data. "One, that IEPs must include how the students' progress toward annual goals will be measured and, two, that IEPs include the extent to which progress is sufficient to enable the student to achieve those goals by the end of the school year" (Gunter, 2003). SIS and LMS systems have built in reporting built by the software vendors. These tend to focus on the most requested information, such as attendance, compliance, demographics, grades, and assessments. Ad-hoc queries are usually available, but require specialized SQL knowledge or learning to use their wiziwig tool. Data analysis on assessments are usually only bi-annual and do not provide the near to real time feedback that is needed to inform instruction. "BI tools allow school leaders to drill down, up, across, and into specific trends; monitor budgets and stay abreast of spending trends; conduct up-to-the-minute analyses; use fast-access critical decision tools; and gain insight into organizational performance." (Endley, 2009)

The United States Department of Education notes:

"Technical challenges can be overcome through research, development, and testing; computing and storage can be budgeted as part of an institution's infrastructure costs. However, implementing data mining and learning analytics in K-20 institutions has costs that go beyond simply computing and storage. Significant human resources also are needed for data preparation, processing, and analysis. Integrating existing data systems, such as grade books, with student information systems can be expensive, and the requirements can exceed the capabilities of the information technology department of a single institution. Our experts reported that at least 70 percent and often 80 to 85 percent of the effort in data analytics is devoted to data cleaning, formatting, and alignment and suggested that education has the further complication of needing to move data across different levels of the system, back and forth between classroom, school, district, and state databases.

If technical challenges can be overcome and data can be prepared and analyzed, smart consumers are needed to use the data. Today, teachers and school leaders are surrounded by many data reports and often are frustrated by how much work is required to sort the useful from the useless. Data dashboards need to be adapted to everyday users. Education researchers and software developers must obtain a good understanding of the challenges from the users' perspective for adoption and implementation of data mining and analytics in classrooms, schools, districts, and other institutions to be successful. This will enable them to pose questions that matter to teachers and other users and to frame findings in a thoughtful, informative way that highlights and recommends clear actions." (Marie Bienkowskie, 2012)

\section{INFRASTRUCTURE NEEDS}

Business intelligence demands infrastructure. Independent behavioral intervention schools need to set up this infrastructure to properly capture data (Burns 2015), as well as the necessary BI tools that need to be implemented to allow data usage. Data reporting needs to be focused on the teacher level, where the interventions and behavior corrections are being made. Previous attempts at data driven decision making in education has been focused on the performance of the school, district, or even state level (Picciano 2012). This does not provide the actionable little data that is necessary for the teachers to utilize and inform instruction.

\section{- Data collection tools}

At the heart of BI, is the data. These institutions need to make the necessary investments to collect the data that is needed for teachers to make informed decisions on instruction (Wagner 2012). Without the data to support decision making, teachers will fall back on intuition or experience. Emotional special education requires data to be collected and analyzed down to a minute interval (Molenar and van Campen 2016). Few tools are available for this and depending on the behavioral instruction model used, can differ in needs. Schools need to develop collaborative with their behavioral model organizations to develop custom tools to record the necessary data. With the absence of these to-be-developed tools, data should be collected through a user interface to a database. This allows data validation, and easy access to the raw data. A last resort would be collection through spreadsheet where data issues, as well as validation and protections are easily overcome and pulling of the data increases in difficulty. 
Data collection also exists in behavioral and formative assessments. The reported on these assessments range from the student, teacher, counselor, and parents. These tools may be state assessments, online academic progress, problem severity and functioning behavioral assessments, or other types of assessments. This data can be stored in databases, spreadsheets, SIS's, and LMS's.

\section{- Data Warehouse}

A data warehouse is essential for creating one true version of the data (Gray 2013). Schools IT departments will need to set up a dedicated database server with the proper warehousing software. Data will be pulled either manually, through backups, or FTP's to the ETL level. At the ETL level, data will be cleansed, filtered, standardized, deduped, and merged. This cleansed, standardized data will then be written to the database where it can be accessed for data analysis. The power of data warehousing and its integration capabilities are described as follows:

Sharing information via data warehousing is like sharing on the floor of the United Nations. Each database is like a different country's ambassador - each speaks a different language and cannot fully understand what the other ambassadors are saying. Technology makes it possible for the U.N. ambassadors to communicate clearly using an extensive network of translators. Speech is translated into several common languages so all can participate. Data warehousing (see figure one) achieves the same level of communication by "translating" the information into a format that can be understood by all of your databases (Levine, 2002, p. 11).

Each component of the BI infrastructure presented in figure one, further suggested the importance of integration of data to provide analytics for education. As discussed previously, special education may have data feeds that require special attention that typically has not been part of the standard data capture of educational institutions. While sensors and smart devices might help special education institutions capture more data integrating subjective assessments, with smart device real time data and with student performance can be especially challenging. Additionally, the presentation layer component may pose further difficulties as combining multi-structured data for reporting purposes presents another level of complexity that business organizations at the cutting edge of technology adoption are still struggling with (Agrawal 2012).

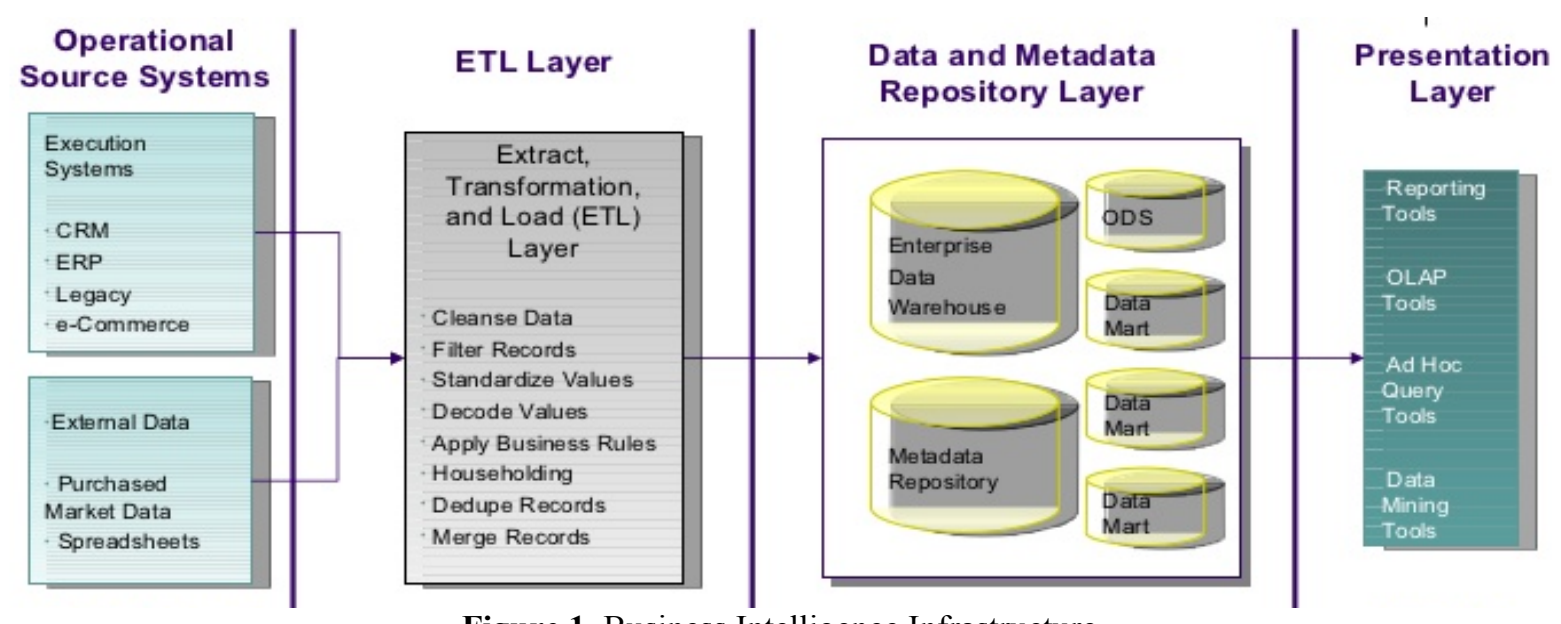

Figure 1. Business Intelligence Infrastructure

Business Intelligence solutions enable users to obtain enterprise-wide information more easily (gray 2013). BI software tightly integrates querying, reporting, OLAP, data mining and data warehousing functions to enable users to obtain "all" the information they desire from their organization's numerous databases. BI software should allow you to derive the transactions and summaries you need without having to know the sources (which databases, which servers, etc.)" (Business Intelligence Software, 2007). Reporting and data analysis of the data needs to be driven by the teachers and accessible by the teachers (Burns 2015). This will allow the teachers to effectively inform 
instruction through the little data. Dashboard and Visual displays with the ability to "dig" into the underlying data, while joining multiple variables into the data. "Dashboards compile key metrics in a simple and easy to interpret interface so that school officials can quickly and visually see how the organization is doing" (Weathers, 2004) This will allow teachers and administrators to drive their analysis and find trends which have historically been impossible or too challenging to complete.

There is a whole host of potential BI providers for educational data such as Tableau and Qlik. With regard to tools, the important aspect of BI is that the tools are designed to be general purpose, and are sold by major vendors in all the vertical markets in which they participate. This means that a degree of customization is likely to be necessary, even if some education specific features are built in, but the trade-off is that the number of data sources that can be included is very wide (Sherlock, 2013). Cost is always a major consideration, especially in small, non-profit centers. The correct software for each program can only be decided by the administration of the school in concert with the end users. The abilities of the end product should focus on dashboards and visual displays. One such product is Tableau Software. It has a fairly quick learning curve and allows the development and analysis of data, while joining multiple data sources and/or tables to really allow the user to dig into the data.

\section{LEARNING ANALYTICS SOLUTIONS}

As indicated previously there is a wide variety of BI tools that can be used as learning analytics solutions. Often times, educational institutions jump straight into integrating and using data with no real thought to the implications of using BI learning analytics tools in education. Considering the various stakeholders involved as well as the ethical moral use of data analysis becomes especially important when considering special education and behavioral intervention in education.

Greller and Drachsler (2012) present a generic framework for the use of learning analytics in education that can be used for the design and development of data integration and analytics (See figure two). This can be useful when considering the development of BI or in other words, a learning analytics solution for behavioral intervention.

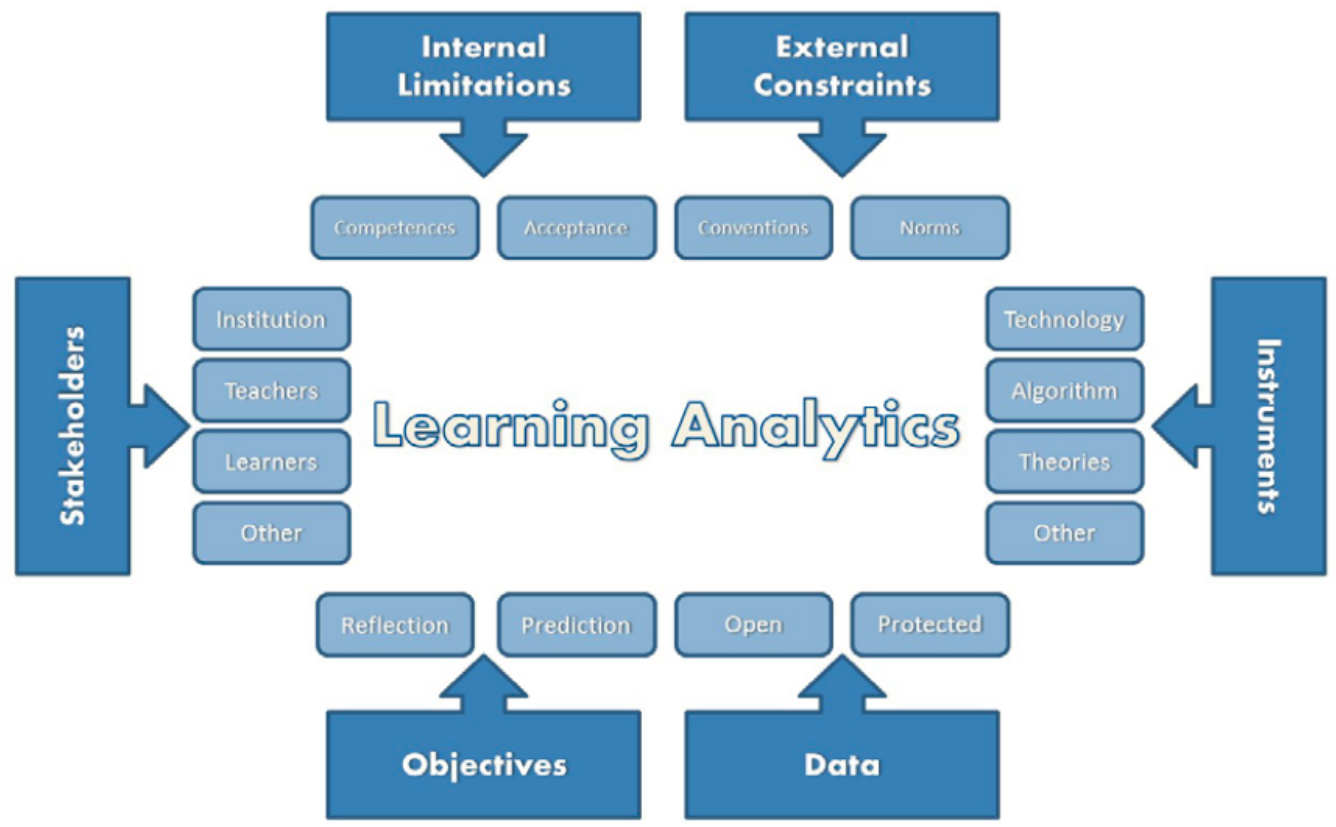

Figure 2. Learning Analytics Dramework (Greller and Drachsler, 2012)

Each of the dimensions presented in the framework should be explored in the context of business intelligence for behavioral intervention in order identify challenges and issues that the designers would face in the development of 
BI infrastructure. Each critical dimension has many instantiations that helps further clarify the impact of a given dimension of the learning analytic measures. For instance, when considering the stakeholder dimension, some instantiations may include the instructor, therapist, parent and the special needs student.

The generic learning analytics framework presented in figure two can be specifically adopted to the use of analytics in behavioral intervention. One use case for learning analytics for special education is described in table two. The use case described in table two for behavioral intervention learning analytics can be used as a checklist when considering what learning analytics measures make most sense, has no moral ethical concerns, as well as proves to be an effective variable to enhance learning and education for students with emotional, behavioral and developmental issues of students.

By identifying the processes and data collection points for intervention education, building each layer of the BI infrastructure platform becomes easier. Integration of the data and instruments dimensions for each possible use case can lead to the implementation of a centralized data store. Awareness of the internal and external constraints will define the manner data can be combined for analysis as well as levels of access given to various stakeholders. While development of learning analytics has challenges from a technical standpoint, the true challenges may come in the form of social political issues where turf wars maybe fought between data owners. Resource allocation in education tends to be challenging and the creation of an analytics framework requires a long term investment. These challenges will continue to stagnate the development of full scale BI solutions in special education. As platforms become less expensive and cloud based analytics solutions become more viable, behavioral intervention education will also be able to gain the benefits of BI and analytics more painlessly.

\begin{tabular}{|l|l|}
\hline \multicolumn{1}{|c|}{ Dimension } & \multicolumn{1}{c|}{ Values } \\
\hline Stakeholders & $\begin{array}{l}\text { Data subjects: a student group with emotional and behavioral learning difficulties. } \\
\text { Data clients: Instructor, therapist. }\end{array}$ \\
\hline Objective & $\begin{array}{l}\text { Reflection: Analyze student interactions in reading for literacy using online application, } \\
\text { identify students who are struggling with the application and provide them with needed } \\
\text { support network. }\end{array}$ \\
\hline Data & $\begin{array}{l}\text { Protected dataset: } \text { Student interaction with the reading application. } \\
\text { Relevant indicators: each reading activity measured in the program. } \\
\text { Time scale: } \text { what time frame is applied to the analysis? }\end{array}$ \\
\hline Exstruments & $\begin{array}{l}\text { Technology: process prediction analysis, statistics. } \\
\text { Presentation: visualization of reading behavior and interaction with application, stats } \\
\text { table. }\end{array}$ \\
\hline Internal limitations & $\begin{array}{l}\text { Conventions: (1) Privacy: is the analysis in accordance with privacy arrangements; are } \\
\text { the parents/guardians of the students properly informed? } \\
\text { (2) Ethics: What are the dangers of abuse/misguided use of the data? } \\
\text { Norms: Are there e.g., legal data protection or IPR issues related to this kind of use of } \\
\text { student data? } \\
\text { Time scale: will the students still be able to benefit from the analytics outcome? Is the } \\
\text { analysis post-hoc or just-in-time? }\end{array}$ \\
$\begin{array}{l}\text { Required competences: } \\
\text { (1) Interpretation: Do the data clients have the necessary competences to interpret and } \\
\text { act upon the results? Do they understand the visualization or presentation of the } \\
\text { information? } \\
\text { (2) Critical thinking: Do they understand which data is represented and which data is } \\
\text { absent? How will they use this information? }\end{array}$ \\
\hline
\end{tabular}

\section{CONCLUSION}

Specialized education centers for emotional, behavioral, and learning disabilities face many challenges to embracing "big data". Schools must understand the value of a data-driven approach to education (West, 2012). Teachers are essential to the success of data usage. They are the front line, and will be utilizing the student data to inform their 
classroom instruction. The expanded data availability and ability to see trends and underlying data as never before offers a better understanding of how their instruction effects learning and behavior treatment. Through the embracing of the collection and reporting of all the students data, all stakeholders will be better informed to make the right decisions, at the right time and ensure the student is in the proper placement for his/her current state.

Through the use of business intelligence, school resources and funds can be directed to the interventions which are backed by data to be the most effective. This resource allocation will pay dividends on the cost vs. outcomes. Teachers will no longer need to rely on their gut feelings when making recommendations. Teacher trust of counter intuitive data may experience significant pushback from the teaching staff at first. Plans for implementation of instructional practices based on data should be established and agreed upon prior to analysis.

The greatest gain from the embrace and implementation of outcomes will be the ability to provide multiple sources of data on the impact of the intervention on the child. Today, schools are forced to provide data on just biannual assessments, or quarterly behavior updates or scoring. With the implementation of a data collection backend and BI tools, a full picture of the progress, gains, interventions, and impact will be able to be shown. This will also enable faster, near-real-time adjustments to the interventions in place for each child, as well as the reduction of the number of variables of interventions. This will ultimately get the students back into their home schools and normal environments.

\section{REFERENCES}

Boardman, J. K. (2011). Addressing the "Research Gap' in Special Eduacation Through Mixed Methods. Learning Disability Quarterly, 208-218.

Aggarwal, A. (2015). Opportunities and Challenges of Big Data in Public Sector. Managing Big Data Integration in the Pubic Sector, 289.

Burns, R. T. (2015). An Application of the Autism Management Platform to Tracking Student Progress in the Special Education Environment.

Chen, C. H., Bobzien, J., Giannakos, M., Bruhn, A., Bruggeman, A., Mohrehkesh, S., ... \& Chrisochoides, N. P. (2015, October). Familiar Video Stories as A Means for Children with Autism: An Analytics Approach. In Healthcare Informatics (ICHI), 2015 International Conference on (pp. 368-373). IEEE.

Ebner, M., \& Schön, M. (2013). Why learning analytics in primary education matters. Bulletin of the Technical Committee on Learning Technology, Karagiannidis, C. \& Graf, S (Ed.), 15(2), 14-17.

Endley, K. (2009). Business Intelligence: Turning Knowledge into Power. School Business Affairs, 27-28.

Gray, P. (2013). Data Warehousing. In Encyclopedia of Operations Research and Management Science (pp. 362367). Springer US.

Gunter, P. (2001). Data-based decision-making to ensure positive outcomes for children/youth with challenging behaviors. In L. B. (Eds.), Addressing social, academic, and behavioral needs within inclusive and alternative settings (pp. 49-52). Reston, Virginia: Council for Exceptional Children.

Jonaganti, T. K. (2008, December 30). Data Warehouse Modeling. Retrieved November 8, 2015, from SlideShare: http://www.slideshare.net/vivekjv/data-warehouse-modeling-presentation/13

Kavale K. A. \& Forness, S. R. (2000). Policy decisions in special education: The role of meta-analysis. In E. P. R. Gersten, Contemporary special education research: Synthesis of the knowledge base on critical instructional issues (pp. 281-326). Mahway: Lawrence Erlbaum. 
Kim, J. Y., Cho, J. R., \& Park, S. G. (2015). Smart Device Experience at Home, Vocabulary and Literacy Skills among Korean Children. In International workshops on the Convergent Research Society among Humanities, Sociology, Science and Technology (HSST).

Levine, E. (2002). Building a Data Warehouse. American School Board Journal, 1.

Long, P., Siemens, G.(2011). Penetrating the Fog: Analytics in Learning and Education. EDUCAUSE Review Magazine. Volume 46. 5. p. 31-40.

Marie Bienkowskie, M. F. (2012). Enhancing Teaching and Learning Through Educational Data Mining and Learning Analytics: An Issue Brief. Washington D.C.: U.S> Department of Education, Office of Educational Technology.

Molenaar, I., \& van Campen, C. K. (2016, April). Learning analytics in practice: the effects of adaptive educational technology Snappet on students' arithmetic skills. In Proceedings of the Sixth International Conference on Learning Analytics \& Knowledge, 538-539. ACM.

National Survey of Childhood Health Data. (2009/10). Survey Results CSHCN with EBD issues. Retrieved November 8, 2015, from Nation Survey of Childhood Health Data: http://www.nschdata.org/browse/survey/results?q=1820\&r=1\&t=1

Picciano, A. G. (2012). The Evolution of Big Data and Learning Analytics in American Higher Education. Journal of Asynchronous Learning Networks, 16(3), 9-20.

Phillip L. Gunter, K. C. (2003). Finding a Place for Data Collection in Classrooms for Stuents with Emotional/Behavioral Disorders. Preventing School Failure: Alternative Education for Children and Youth, 4-8.

Scientific Learning. (2015, January 05). 10 Trends to Watch in Special Education in 2015. Retrieved Novemeber 8, 2015, from Scientific Learning: http://www.scilearn.com/blog/2015-special-education-trends

Sherlock, W. K. (2013). Analytics Tools and Infrastructure. Bolton, UK: CETIS for Jisc.

Wagner, Ellen, and Phil Ice. (2012).Data Changes Everything: Delivering on the Promise of Learning Analytics in Higher Education. Educause Review, 47(4), 32.

Weathers, J. S. (2004). Dashboard Lights: Monitoring Implementation of District Instructional Reform Strategies. Philadephia: University of Pennsylvania Consortium for Policy Research in Education.

West, D. M. (2012). Big Data for Education: Data Mining, Data Analytics, and Web Dashboards. Washington DC: The Brookings Institution.

Whitehurst, G. J. (2002). Evidenece-based education. Student Achievement and Accountability Conference. 